\title{
Expanding economic perspectives for sustainability in urban water and sanitation
}

Authors:

Kumudini Abeysuriya, Cynthia Mitchell \& Juliet Willetts

Abstract:

The economic principles and tools that are commonly applied to recover costs for urban water and sanitation arise from the dominant perspective of neoclassical economics. In this paper we argue that this perspective, with its emphasis on 'full cost pricing' based on the 'user pays' principle, is too limited for sustainability. We examine two other qualitatively different economic perspectives to demonstrate how they lead to different approaches: ecological economics takes a more holistic approach explicitly committed to sustainability, while Buddhist economics brings ethics to the fore and opens the possibility for cooperation between the various actors in creating solutions to benefit individuals, society and the environment. We propose a set of interconnected guiding principles based on an expanded economic perspective that integrates all three perspectives, to enable water and sanitation services for developing countries to align with sustainability. 


\section{Introduction}

According to Daily and Ehrlich (1996), sustainability is implied when processes or conditions "can be maintained indefinitely without interruption, weakening, or loss of valued qualities". A key requirement for the continuous provision of goods and services is that resources expended in association with these processes and conditions must be replenished (or substituted) so that the necessary resources continue to be available.

To discuss sustainability in urban water and sanitation services in more commonly used language, the above may be posed as a requirement that costs are recovered. In this statement, 'costs' must be understood in their broad sense as all resources utilised in the provision of these services - material resources as well as capacities to provide associated services and functions, such as ecosystem services.

A range of qualitatively different costs can be incurred, most commonly described as a combination of monetary costs, environment costs and social costs. Monetary costs are measurable in dollar or equivalent terms, and consist of direct costs and a range of other costs which are artefacts of policy, accepted accounting methodology, or commercial and institutional arrangements. Environmental costs are "connected with the actual or potential deterioration of natural assets due to economic activities” (United Nations 1997).

Environmental deterioration occurs then humans deplete resources and create waste at rates that exceed the capacity of the environment to regenerate, assimilate and recover. Social costs are the impacts on people. Unlike monetary costs, environmental and social costs are multidimensional and non-additive.

Recovering costs in line with sustainability would mean that monetary costs are quantified and revenues are raised to recover them, and that impacts on environments are limited to lie within the natural capacity of ecosystems to regenerate resources and assimilate wastes. The idea of 'recovering' social costs is more complex, because societies may respond to impacts by choosing to adapt and change rather than requiring restoration or compensation, especially if benefits are perceived to outweigh costs. Nevertheless, cost recovery would also mean that impacts on society would be explicitly identified and addressed, most defensibly through a process involving deliberative public participation.

In this paper we contend that different economic perspectives and worldviews indicate different approaches to cost recovery, and examine the extent to which three different economic perspectives respond to the requirement for sustainability within our broad definition of costs and cost recovery. We argue that the dominant perspective of neoclassical economics (NCE) is insufficiently aligned with sustainability as envisaged above, being limited by its emphasis on cost recovery through 'full cost pricing' and large scale technological solutions. We propose that ecological economics (EE) and Buddhist economics (BE) can each contribute to an expansion of perspective that better enable sustainability and cost recovery, while complementing each other. Cost recovery aligned with sustainability is enabled by an expanded perspective that is an integration of the three perspectives. 


\section{Neoclassical economic perspective}

NCE is the dominant economic perspective underpinning government policies in industrialised countries around the world today, and more recently, in developing countries advised by multilateral lending agencies. It is often referred to as 'market economics' because of its preference for the market as the means of allocating scarce resources (Daly \& Farley 2003, p. 3).The NCE approach is characterised by reduced government spending, reduced government provision of welfare, and reduced taxes, along with privatisation of state enterprises - a strategy credited with spectacular increases in gross domestic product since its increasing adoption since the 1970s (Schwartz 2005).

Price is the principal communication tool in a market (Edwards-Jones, Davies \& Hussain 2000), making pricing the mechanism of choice for revenue raising in the NCE model. Thus 'full cost pricing' and the 'user pays principle' where revenues to recover all costs are raised through charges to users of services, are fundamental values in NCE. Including all monetary costs in the price would mean that revenues raised from users would be sufficient to recover costs incurred by service suppliers. NCE premises that environmental and social can be 'internalised' by converting them into monetary equivalents for inclusion in the price, that would lead to changes in consumption patterns in ways that reduce these costs.

NCE approaches in the water and sanitation sector are promoted as "internationally accepted" policies that include the "[separation of] service provision from government"; "financ[ing] services through user charges, not from general tax revenues"; and "full cost recovery” through 'full cost pricing' based on the 'user pays principle' (Walker 2003). It has been accompanied by greater private sector participation in the sector.

The effectiveness of the NCE approach for water and sanitation must first be questioned through asking whether 'user pays' is a fair and just principle in the context. We see the 'user pays' principle as a special case of the 'beneficiary pays' principle which is consistent with notions of distributive justice, namely that all those who benefit from a service should pay for it. In the case of water supply, Seregeldin (1994 as quoted by McGranahan et al. 2001, p. 99) argues for the 'user pays' principle on the basis that " "private' benefits constitute the bulk of the overall benefits of a household water supply", although the ongoing debate demonstrates there is little consensus on this issue (Gleick et al. 2002; McNeill 1998). There is less ambiguity in the case of sanitation, however, since a significant proportion of its benefits are public. Sanitation provides critically important benefits of protecting public health, the environment and water resources through appropriate disposal of waste, which are additional to the private benefit of sanitary waste removal from the user's immediate domain. Thus we argue that the 'user pays' principle with pricing as the sole mechanism for recovering 'full costs' cannot be defended: governments have a clear responsibility to account for the public benefits.

Secondly, we ask if NCE limits environmental costs to levels that are sustainable. While the legitimacy of internalising environmental costs by converting multidimensional environmental impacts to their alleged monetary equivalents is itself disputed (Söderbaum 2003), NCE's objective in doing so is to achieve a level of environmental damage that is economically efficient - when the marginal private costs of reversing damage is equal to the marginal social costs of such damage (Edwards-Jones, Davies \& Hussain 2000, pp. 226- 
228). Limiting environmental costs to levels that allow ecosystems to recover are thus not an explicit goal in NCE.

Finally, neoclassical economists are often characterised as having an ideological reliance on advanced technological solutions to solve environmental and social problems (Smith, Lyons \& Sauer-Thompson 1999), thus indicating large scale, sophisticated and costly water and sanitation infrastructure. In most cases these are very expensive even for industrialised societies, and simply unaffordable to societies in developing countries. Furthermore, ideological commitment to costly large-scale systems has often aggravated the problem of services being unavailable to poor communities (Stockholm Water Symposium Statement 2002, Principle 3).

Our analysis above shows that the NCE approach is limited in its capacity to effectively recover monetary or environmental costs necessary to support sustainable water and sanitation in developing countries.

\section{Ecological economic perspective}

Ecological economics (EE) has emerged as a response to the problematic consequences of economic development (Costanza et al. 1997; Söderbaum 2000), largely driven by the limited perspective of NCE. EE expands this perspective by making an explicit commitment to sustainability, seeking to locate economic thinking within the biophysical constraints of a finite planet to enable sustainable development (Costanza et al. 1997; Daly \& Farley 2003; Edwards-Jones, Davies \& Hussain 2000). It advocates a 'conceptual pluralism' that stresses dialogue and learning between stakeholders holding different values, ideologies and perspectives (Söderbaum 2000). EE therefore does not reject NCE, but calls for constraining its domination in influencing policy when it obstructs sustainable development (Daly \& Farley 2003, pp. 4-5). EE is committed to ethics as decision-making that meets the interests of present generations and future generations of all life on the planet (Costanza et al. 1997; Söderbaum 2000).

We highlight two of EE's principles with implications for sustainability in water and sanitation here, noting that a broader description of EE is beyond the scope of this paper. First, EE emphasises sustainable scale for economic activities so they occur within the planet's carrying capacity. Seeking to address problems at the smallest domain in which they can be solved is another of EE's guiding principles (Daly \& Farley 2003), that indicates policy to support a range of technological scales that are as small in physical scale as possible taking into account the context and the objective to limit degradation of the environment.

Second, EE recognises the constraints on the economy imposed by natural laws, the second law of thermodynamics or entropy law in particular. It states the irreversibility of transformations of matter and energy in everyday processes as a gain in entropy, making low entropy matter-energy the ultimate or most fundamental means for achieving human ends (Daly \& Farley 2003, pp. 38, 48). Nature supports and maintains the supply of low-entropy matter-energy through cyclic flows in the earth's natural processes driven by the sun (such as in the water cycle, nutrient cycle, nitrogen cycle and carbon cycle). Sustainability is improved by frugal use of available supplies of low-entropy matter-energy, and choosing 
technological processes that keep entropy gain as low as possible (Costanza et al. 1997; Daly \& Farley 2003). EE therefore indicates designing processes where materials flow in cycles with as little mixing, dilution and dispersal as possible, and use as little energy as possible.

EE provides a theoretical rationale for new directions emerging for urban water and sanitation infrastructure. The new paradigm enables assessment of decentralised and distributed options that are tailored to contexts on an equal basis with conventional 'onesize-fits-all' centralised options (Mitchell et al. 2007): options such as stormwater retention for aquifer recharging and rainwater harvesting for water supply, and a host of small scale sanitation strategies that reduce dilution of wastes in water and recycle nutrients back to the soil, treat wastewater close to where it is produced, and facilitate re-use of treated wastewater. Such options provide greater opportunities to conserve low-entropy matterenergy through careful design of technological processes.

EE facilitates cost recovery aligned with sustainability, firstly by stressing the requirement for water and sanitation infrastructure to operate within the carrying capacity of ecosystems - consistent with the 'recovery' of environmental costs. Daly (1992) observes this scientifically uncertain ecological limit must be "a social decision”, decided on through dialogue, consistent with EE's conceptual pluralism, which creates a forum for addressing social costs. Finally, decentralised and distributed arrangements can create multiple output products that potentially create multiple revenue streams that can make recovery of all monetary costs more feasible.

\section{Buddhist economic perspective}

We submit that Buddhist economics provides a further expansion of the economic perspective for water and sanitation, which aligns with and supplements the contribution of EE. Buddhist economics (BE) refers to the collective economic ideas dispersed through the Buddhist scriptures, dealing with the management of material wealth consistent with Buddhist philosophy (Daniels 2003; Payutto 1992; Schumacher 1973).

$\mathrm{BE}$ articulates a universal law that nothing is absolute: everything is conditioned, relative and interdependent - which emphasises relationality between all things, including individuals, society and environment of the present, past and future (Payutto 1992; Rahula 1996). BE brings ethics to the centre of economic activity as a result of the karmic law of cause and effect: the ethical quality of intentions and actions underpinning an activity define the nature of their consequences as "beneficial” or "harmful” (Payutto 1992).

For water and sanitation services to contribute to wellbeing from the BE perspective, they should thus be driven by ethical motivations and seek to cause no harm to individuals, to create no agitation in society, and to have a benign impact on the environment. Below, we outline what we see this to imply in more specific terms.

We propose that BE implies dialogue amongst stakeholders in deciding on water and sanitation arrangements, concurring with $\mathrm{EE}$ and extending its rationale. While ethical motivations are challenging to establish or evaluate, we contend that genuine participatory processes as envisaged by the deliberative democracy discourse can potentially create collective 'right motivation' aligned with BE. Such processes create space where actors traditionally in competition for resources and power can begin to build cooperative 
relationships, "united in their ignorance of how best to improve the general situation that brings them together” (Fung \& Wright 2003).

Inclusive dialogue also enables the BE notions of relationality and interdependence to be brought to the fore, between participants in dialogue as well as wider stakeholders including the environment. Systems that foster social cohesion, human dignity and freedom and environmental care (Schumacher 1973) align with the need to cause 'no harm'. BE requires that the environment should be treated with reverence (ibid), indicating demands on the environment be kept well below its carrying capacity - consistent with EE's call for sustainable scale.

A Buddhist economy has frequently been interpreted as one that specifies organisation at a contextually appropriate scale - neighbourhood scale arrangements and intermediate technologies with local resources supplying local needs, and cooperative, nurturing social environments (Ariyaratne 1999; Daniels 2003; Schumacher 1973). We see this as equivalent to society's collaboratively choosing to live within its economic, environmental and social means.

BE shifts the expectations of the three main groups of actors - government, customers, and service providers, who are relational with each other and wider society and the environment. It calls service providers to be service-oriented, committed to the wellbeing of society and the environment they are in relation with - a commitment that may ultimately determine the company's long term future. It calls on individuals to cooperate with service providers, with

a willingness to pay a fair price for the services they receive, and with caring behaviours that support the proper operation of the physical systems that provide water and sanitation services. Finally, it calls on governments not to abdicate responsibility for public welfare, and therefore, to compensate service providers for the societal and ecological benefits delivered.

\section{An expanded perspective by integration}

One of NCE's prime concerns is with efficiency in allocating scarce resources to drive economic growth (Daly \& Farley 2003), which we see as a key limitation in its perspective for indicating sustainable water and sanitation systems. EE and BE, like NCE, are concerned with efficiency - using the least means to reach desired ends (Schumacher 1973) - but they are equally concerned with effectiveness, i.e., not only concerned with 'doing the thing right', but with 'doing the right thing'. EE asks the effectiveness question taking a number of perspectives into account, leading it to be concerned with the physical limits of the planet, distributional effects and justice issues. BE asks the effectiveness question in light of how relationality and ethics are incorporated to achieve beneficial ends.

Thus we argue that $\mathrm{EE}$ and $\mathrm{BE}$ are able to expand the dominant but limited perspective of NCE which neglects key characteristics of the world and human capacity for sustainability. They are collectively able to indicate a set of guidelines for water and sanitation that is aligned with sustainability while limiting NCE to its domain of applicability. We propose four interconnected principles based on such an integrated perspective: 
i. Arrangements for water and sanitation should emphasise cooperation between stakeholders. Planning through cooperative and deliberative processes that bring the diverse knowledges and interests of stakeholders such as planners, professional experts, service providers, service recipients, government agents and the public together is likely to lead to decisions that are fair and survive time (Costanza et al. 1997). Such processes provide a forum to address social impacts, and to highlight relationality and simultaneously seek wellbeing of individuals, society and the environment.

ii. Ethics and "goodness" should underpin decision processes and choices. The goal of water and sanitation services would then be to enhance the quality of life of individuals in the community without causing harm to others, avoiding excessive costs rather than imposing them on future generations.

iii. Efficiency goals should include entropy considerations for the resources used, including water, nutrients, and energy. Then efforts would be made to design material flows in closed loops using as little energy and few non-recycling materials as possible. It would for example explore local water supplies, returning excreted nutrients to agriculture in a sanitised and useable form, decreasing or even eliminating the use of water in sanitation, and treating any water that is used so its quality and quantity cause no ecosystem degradation, using technologies that have low requirements for energy and other resources.

iv. Society should manage water and sanitation to support living within its economic and environmental means. They would lie within the economic means of the community, of appropriate financial scale so costs are recoverable. Physical systems would be designed to lie within the carrying capacity of local and global ecosystems. Efficiency would be sought, that increases individual, societal and environmental wellbeing with fewer input resources and their re-use multiple times.

\section{Conclusion}

While neoclassical economics has delivered significant benefits in many areas, its approaches have increased ecosystem degradation, poverty and injustice by not paying adequate attention to ecological limits and social constraints (Smith, Lyons \& SauerThompson 1999). NCE attempts to address these problems have led to little success due to its narrow focus on economic growth.

We have argued that drawing on ecological economics and Buddhist economics can lead to an expanded economic perspective for guiding urban water and sanitation services for developing countries. EE emphasises ecological limits and social justice through democracy, that indicate decision-making through public participation, and technological processes that limit entropy gain and keep environmental impacts within the carrying capacity of ecosystems. BE stresses relationality between all individuals, wider society and the environment, that indicates cooperation based on ethics and caring for all.

Finally we have proposed a set of guiding principles based on an integrated economic perspective, to indicate the type of services and decision-making processes suitable for 
developing countries, that align with sustainability by consciously remaining within the economic and environmental means of the society they serve. 


\section{References}

Ariyaratne, A.T. 1999, Schumacher Lectures on Buddhist Economics, Sarvodaya Vishva Lekha, Ratmalana, Sri Lanka.

Costanza, R., Cumberland, J., Daly, H.E., Goodland, R. \& Norgaard, R. 1997, An Introduction to ecological economics, St. Lucie Press, Boca Raton, Fla.

Daily, G.C. \& Ehrlich, P.R. 1996, 'Socioeconomic Equity, Sustainability, and Earth’s Carrying Capacity', Ecological Applications, vol. 6, no. 4, pp. 991-1001.

Daly, H.E. 1992, 'Allocation, distribution, and scale: towards an economics that is efficient, just, and sustainable', Ecological Economics, vol. 6, no. 3, pp. 185-193.

Daly, H.E. \& Farley, J.C. 2003, Ecological economics : principles and applications, Island Press, Washington, D.C.

Daniels, P.L. 2003, 'Buddhist economics and the environment: Material flow analysis and the moderation of society's metabolism', International Journal of Social Economics, vol. 30, no. 1/2, pp. 8-33.

Edwards-Jones, G., Davies, B. \& Hussain, S. 2000, Ecological economics : an introduction, Blackwell Science, Malden, Mass.

Fung, A. \& Wright, E.O. 2003, 'Thinking about Empowered Participatory Governance', in A. Fung \& E.O. Wright (eds), Deepening democracy : institutional innovations in empowered participatory governance, Verso, London, p. .

Gleick, P.H., Wolff, G., Chalecki, E.L. \& Reyes, R. 2002, 'The Privatization of Water and Water Systems', in, The World's Water 2002-2003: The biennial Report on Freshwater Resources, Pacific Institute for Studies in Development, Environment, and Security, Oakland, California.

McGranahan, G., Jacobi, P., Songsore, J., Surjadi, C. \& Kjellen, M. 2001, The Citizens at Risk : from Urban Sanitation to Sustainable Cities, Earthscan, London ; Sterling, VA.

McNeill, D. 1998, 'Water as an economic good', Natural Resources Forum, vol. 22, no. 4, pp. 253-261.

Mitchell, C., Fane, S., Willetts, J., Plant, R. \& Kazaglis, A. 2007, Costing for Sustainable Outcomes in Urban Water Systems: A Guidebook, CRC for Water Quality and Treatment Research Report No. 35, ISBN 1876616601.

Payutto, P.A. 1992, 'Buddhist Economics: A Middle Way for the Market Place', $<$ http://www.urbandharma.org/udharma2/becono.html $>$.

Rahula, W. 1996, What the Buddha Taught, Buddhist Cultural Centre, Dehiwala, Sri Lanka.

Schumacher, E.F. 1973, Small is Beautiful : Economics as if People Mattered, Harper torchbooks, TB 1778.

Schwartz, N.D. 2005, 'Prosperity without Peace: Israel Rises', Fortune, vol. 151, no. 10, pp. 46-51.

Smith, J.W., Lyons, G. \& Sauer-Thompson, G. 1999, The bankruptcy of economics : ecology, economics and the sustainability of the earth, Macmillan Press.

Söderbaum, P. 2000, Ecological economics : a political economics approach to environment and development, Earthscan, London.

Söderbaum, P. 2003, 'Ecological economics for water policy and management: a need for major shifts in thinking', Water Science \& Technology, vol. 47, no. 6, pp. 33-41. 
Stockholm Water Symposium Statement 2002, 'Urgent Action Needed for Water Security: 2002 STOCKHOLM STATEMENT', $<$ http://www.siwi.org/pdf/2002_Stockholm_Statement.pdf $>$.

United Nations 1997, Glossary of Environment Statistics. Studies in Methods: Series F, No. 67, United Nations, New York,

Walker, I. 2003, 'PRC Wastewater Tariffs and Management Study', ADB, $<$ http://www.adb.org/Water/Seminars/blue_bag_11.asp $>$.

\section{Authors' biography:}

Kumudini Abeysuriya is a Senior Research Consultant at the Institute for Sustainable Futures (ISF), and recently submitted her PhD thesis titled A Pathway to Sustainability in Urban Sanitation for Developing Asian Countries on which this paper is based. Associate Professor Cynthia Mitchell is a Research Director as ISF where she provides thought leadership on diverse aspects of sustainability education, water cycle management and green buildings. Dr. Juliet Willetts is a Research Principal at ISF with extensive experience in research to instigate policy and practice change in the areas of sustainable water management and international development. 